\title{
Os cadernos de laboratório de Pasteur: uma reflexão sobre o público e o particular nas biografias de cientistas
}

\author{
Notebooks from the Pasteur laboratory: some \\ reflections on the public and private in the \\ biographies of scientists
}

\author{
Moema de Rezende Vergara \\ Pesquisadora do Museu de Astronomia e Ciências Afins \\ Rua Gago Coutinho, 60/505 \\ 22221-070 Rio de Janeiro - RJ Brasil \\ moema@mast.br
}

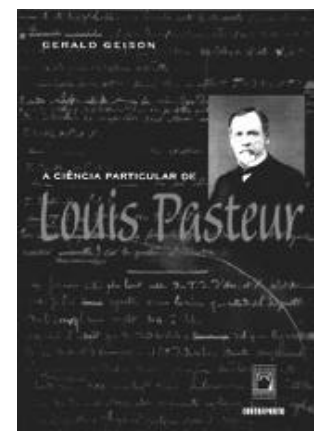

Gerald Geison A ciência particular de Louis Pasteur Rio de Janeiro, Contraponto/Fiocruz, 2002, 456p.
A historiografia da ciência, influenciada pela abordagem social studies of science, tem lançado mão de registros de laboratório como fonte privilegiada para construir uma história que pretende "restabelecer uma simetria total de tratamento entre os vencidos da história das ciências e os vencedores, esses famosos retificadores e revolucionários sempre brandindo a guilhotina do corte epistemológico" (Latour et al., 1997, p. 23). Nesta vertente de pesquisa é que se insere A ciência particular de Louis Pasteur, de Gerald Geison, professor de história da ciência em Princeton, falecido há dois anos, cujo mote principal é a 'desconstrução' do mito pasteuriano. O mérito do livro está em divulgar um corpo documental ainda inédito, que o próprio autor convida pesquisadores futuros a continuar explorando. O aparecimento das notas de laboratório, que durante quase um século, a pedido do próprio Pasteur, ficaram guardadas longe dos olhos do público, ocorreu em 1971. Após a morte de seu neto, Pasteur Vallery-Radot, as notas foram doadas à Biblioteca Nacional de Paris. Consistem em registros criteriosos e pormenorizados de experimentos realizados pelo cientista e seus colaboradores durante quarenta anos de pesquisa ativa e quase diária. Sem dúvida alguma seduzido por essa documentação, Geison deixou escapar fascinado: "É como se espiássemos por cima de seu ombro enquanto ele projeta e executa experimentos que vão do trivial ao profundo" (p. 22).

Uma boa parte da historiografia do século XIX encontrou na narrativa biográfica o gênero por excelência para o registro dos 'grandes vultos'. Na história da ciência, bem como na da arte, há um interesse constante pela história pessoal, com o objetivo de reconstituir a trajetória de 'uma inteligência fora do comum'. Este gênero ofereceu a possibilidade de selecionar fatos significativos que acentuariam o caráter exemplar das biografias, privilegiando a dimensão pública em relação à dimensão privada. Assim, na história da ciência, o gênero biográfico corroborava a celebração do 'gênio' invariavelmente rotulado como "homem fora ou à frente de seu tempo" (Figueirôa, 2001, passim), imune às paixões e aos apelos 'mundanos', para enfim nos colocar face a face com a figura do cientista 'desinteressado'. O valor do trabalho de Geison reside em dar, a partir dos cadernos de laboratório, uma idéia do processo de aquisição do conhecimento científico de Pasteur, que envolvia muitas vezes dúvidas, disputas, medo e competição. 
O livro A ciência particular de Louis Pasteur parte do momento histórico do personagem, mobilizado pela ascensão e queda de Luís Napoleão, pelos acontecimentos da guerra franco-prussiana e pelo advento da República; traça em seguida um minucioso painel das principais pesquisas de Pasteur - das pesquisas dos cristais das quais derivaram suas posteriores considerações sobre a fermentação, a corrida pela vacina contra o carbúnculo e o processo de obtenção da vacina anti-rábica, para qual foram feitos os primeiros testes humanos da história da medicina; e termina analisando a construção do mito pasteuriano. Em todos esses momentos os cadernos de laboratório são utilizados para confrontar ou complementar as demais fontes disponíveis sobre o assunto.

Para Geison a distinção entre ciência pública e particular estaria na simples separação entre o que foi e o que não foi publicado. Segundo o autor, 'ciência particular' seria a atividade científica que ocorre nos 'bastidores'. Contudo Geison confunde a idéia de 'bastidor', espaço anterior à cena vista pelo público, com a de 'particular', que tem a acepção de 'pertencer privadamente a certas pessoas ou coisas'. Diferentemente da pura privacidade, a idéia de 'bastidor' supõe um processo que se destina à publicação. Neste sentido, uma ciência particular é uma contradição em termos, pois uma 'ciência privada' é tão impensável como uma linguagem particular inteligível apenas para seu criador (Knorr-Cetina, 1999, p. 378). O caráter necessariamente público da atividade científica manifesta-se em duas instâncias: na divulgação entre os pares, uma vez que a ciência moderna é um empreendimento coletivo que depende da aprovação e dos resultados obtidos pela comunidade científica; e na vulgarização científica, quando se traduz o conteúdo científico para o público leigo, em busca de apoio e legitimação da atividade científica junto à sociedade em geral.

Essa dimensão pública intrínseca à prática científica passa desapercebida por Geison, que via em Pasteur um cientista francamente ambicioso e oportunista em seus vários esforços de divulgação e de vulgarização científica. Para o bem ou para o mal, o esforço de Pasteur foi amplamente recompensado: não podemos nos esquecer que, no início da década de 1880, quando as vacinas contra o cólera das galinhas e o carbúnculo saíam de seu laboratório, Pasteur estava recebendo 10\% ou mais das verbas governamentais dirigidas a todas as pesquisas científicas na França.

Melhor do que nos mostrar aspectos de uma 'ciência particular', Geison nos traz uma história rica de elementos sobre uma 'ciência pública' na trajetória de Pasteur, quando analisa os vários debates em que tomou parte em sua carreira. Um exemplo desta análise está nas polêmicas travadas, nos anos 1850-60, sobre geração espontânea, tendo a Academia de Ciências de Paris como palco privilegiado de discussões. O debate estava inscrito em um contexto religioso e político de uma França conservadora de meados do século XIX, quando havia uma percepção generalizada de que, de algum modo, a teoria da geração espontânea fazia parte de doutrinas políticas e religiosas perigosas, como o materialismo e o evolucionismo. Assim, quando Pasteur refutou essa idéia, a partir da experimentação científica, ele estava atendendo às expectativas de vários setores da sociedade francesa do Segundo Império, momento de forte união entre Igreja e Estado. Geison enumera os vários recursos utilizados por Pasteur para provar a existência de germes atmosféricos e, assim, refutar definitivamente a teoria da geração 
espontânea, como os procedimentos experimentais com os frascos de pescoço de ganso na polêmica com Pouchet. Não satisfeito em realizar esses experimentos no nível do solo, Pasteur enviou expedições complexas e espetaculares à cordilheira do Jura e à geleira próxima de Montanvert, nos Alpes, dois mil metros acima do nível do mar, para refutar os heterogeneticistas. Pasteur não se restringiu a falar apenas aos seus pares da Academia de Ciências, mas dirigiu-se a diversos segmentos da sociedade francesa, como na ocasião em que discursou perante a princesa Matilde para demonstrar que a geração espontânea não era apenas um perigo político e religioso, mas um erro científico. Para tal, o cientista utilizou vários 'efeitos especiais', como projetores, micrógrafos, bolas de algodão, substâncias químicas ebulientes, recursos de som e luz. Este 'arsenal retórico' foi importante para popularizar sua teoria e, assim, conseguir apoio e legitimidade para suas pesquisas científicas.

No livro de Geison vemos como o debate científico foi importante para o amadurecimento intelectual de Pasteur. O médico e cientista inglês Charlton Bastian reabriu a discussão sobre geração espontânea, afirmando que era possível produzir microrganismos 'espontaneamente' na urina neutra e alcalina. Pasteur estabeleceu um debate público com Bastian nas páginas da revista Nature. Um dos colaboradores de Pasteur, Émile Duclaux, relatou que os embates com Bastian, apesar de algumas falhas em seus experimentos, fizeram com que Pasteur buscasse uma compreensão mais exata da distribuição relativa dos germes no ar, na água e nos objetos sólidos e, o que é mais importante, reavaliasse a resistência de muitos microrganismos ao calor.

Essa passagem nos faz ver que a polêmica é uma relevante instância do processo científico, obrigando o cientista a ir a público para especificar e determinar o que estava implícito e impreciso em suas formulações. Para o historiador a análise das polêmicas é de extrema importância, pois nelas podemos ver como as teorias e o contexto social da época se uniram: elas revelam os interesses políticos e intelectuais subjacentes à prática científica (Dascal, 1999, p. 69). Em seu esforço para desconstruir o mito pasteuriano, Geison pontua sua biografia com as polêmicas que Pasteur enfrentou durante toda a sua carreira. Tais embates nem sempre se deram no plano teórico, mas em alguns casos foram instigados pelo desejo de primazia em determinada área, como no caso da disputa de Pasteur com o veterinário Toussaint sobre a vacina contra a carbunculose, doença que ameaçava os rebanhos de ovelhas.

Após comentar o sucesso de Pasteur na produção de vacinas contra doenças dos animais, Geison nos fala da esperança, à época, de que ele desenvolvesse vacinas contra doenças humanas. De fato, a primeira vacina humana produzida em laboratório foi a anti-rábica elaborada por Pasteur, o que muito favoreceu sua aura de 'salvador' da humanidade. Geison pondera que, naquele momento, a raiva tinha um lugar especial na imaginação popular, como uma doença misteriosa e aterradora. Um dos primeiros obstáculos estava justamente nos procedimentos da experimentação, que, permitida nos animais, era considerada criminosa no homem. Apesar disso, sabendo que Pasteur estava realizando pesquisas sobre esta doença em seu laboratório, autoridades sanitárias e parentes de pessoas feridas procuravam o cientista para submeter as vítimas de animais raivosos ao tratamento, mesmo seu estudo ainda não estando concluído. 
Para ultrapassar a barreira da ética da experimentação e desenvolver suas pesquisas, teve que fazer uso de recursos retóricos de persuasão. O estudo do emprego da retórica na prática científica pode oferecer um instrumental de análise para a interpretação dos vários agentes engajados no processo de difusão do conhecimento científico, interessados em buscar legitimidade e suporte para as atividades científicas. A retórica permite o entendimento público da ciência, ao transpor em linguagem acessível aos leigos o conhecimento científico, dentro dos parâmetros éticos. No caso da ciência, o recurso à retórica, muitas vezes, contribuiu para a revisão ou ampliação destes parâmetros morais e éticos (Gross, 1994, pp. 19-20).

O episódio da vacina anti-rábica seria um caso bastante ilustrativo do uso da retórica, uma vez que inicialmente Pasteur falava muito pouco de seus experimentos, para dificulatar avaliações ou reproduções independentes do tratamento anti-rábico; em contrapartida, discursava muito, de modo a atrair credibilidade e verbas para o aprimoramento da vacina. Tal procedimento 'retórico', em um determinado estágio da pesquisa, foi estratégia importante para garantir o funcionamento do Instituto Pasteur. A instituição foi construída e inicialmente mantida por doações particulares e oficialmente inaugurada em novembro de 1888, "três anos depois de Pasteur anunciar a aplicação de sua vacina anti-rábica em casos humanos" (p. 252). Quando o cientista morreu, em 1895, cerca de 20 mil pessoas tinham-se submetido a seu tratamento contra a raiva em centros espalhados por todo o mundo. E o Instituto Pasteur, em Paris, concebido desde o início como um centro de pesquisa fundamental e também de tratamento da hidrofobia, tem desde então desempenhado papel de destaque na história da ciência e da medicina.

O valor de A ciência particular de Louis Pasteur está em mostrar um lado pouco explorado pela hagiografia do cientista, ou seja, o do homem que tem vaidade, medo e desejo de glória e que por isso omite determinados resultados, desconsidera alguns riscos humanos em suas experimentações e não dá todo o reconhecimento aos seus colaboradores. Mais do que simplesmente expor aspectos particulares da vida de Pasteur, Geison nos faz refletir sobre alguns aspectos do cotidiano do historiador: o cuidado com as fontes, a riqueza e armadilhas da narrativa biográfica e a relação entre ciência e público.

\section{REFERÊNCIAS BIBLIOGRÁFICAS}

Dascal, Marcelo

1999

Figueirôa, Silvia 2001

Gross, Alan

1994

Knorr-Cetina, Karin 1999

Latour, Bruno et al. 1997
'A polêmica na ciência'. Em Gil, Fernando (org).

A ciência tal qual se faz. Lisboa, Sá da Costa.

'Para pensar as vidas de nossos cientistas tropicais'. Em A. Heizer et al. (org.). Ciência, civilização e impérios nos trópicos. Rio de Janeiro, Access.

'The role of rhetoric in the public understanding of science'.

Public Understanding of Science, vol. 3, pp. 3-23.

'A comunicação na ciência'. Em Fernando Gil (org).

A ciência tal qual se faz. Lisboa, Sá da Costa.

A vida de laboratório: a produção dos fatos científicos. Rio de Janeiro, Relume Dumará. 